\title{
CAPÍTULO 23: PLANTA BAIXA PADRÃO PARA AGROINDUSTRIALIZAÇÃO DO MEL NO ESTADO DO MARANHÃO COM VISTAS À GERAÇÃO DE RENDA PARA AGRICULTORES FAMILIARES
}

\section{CHAPTER 23: LOW STANDARD PLANT FOR HONEY AGROINDUSTRIALIZATION IN THE STATE OF MARANHÃO WITH VIEWS OF INCOME GENERATION FOR FAMILY FARMERS}

\author{
Alanna Raíssa de Araújo Silva ${ }^{1}$; Celly Sousa Corrêa ${ }^{2}$; Aline Brito Silva ${ }^{3}$; Danilo Cutrim Bezerra ${ }^{4}$; \\ Nancyleni Pinto Chaves Bezerra ${ }^{5}$
}

\begin{abstract}
Resumo
Objetivou-se elaborar uma proposta de planta baixa padrão para agroindustrialização do mel no estado do Maranhão com vistas à geração de renda para agricultores familiares. Para a efetivação do estudo, este foi realizado em duas etapas: (i) pesquisa documental para a caracterização socioeconômica dos agricultores familiares por meio de levantamento de informações na agência de defesa agropecuária do estado; e, (ii) elaboração de planta baixa individual padrão respeitando as normas da engenharia e da produção segura de alimentos, mas, congruentes à situação sócio-econômica da população avaliada. Com a caracterização do perfil socioeconômico obteve-se as seguintes informações: (i) dominância do gênero masculino na atividade; (ii) predominância do ensino fundamental incompleto; (iii) maioria compreendida na faixa etária de 41 a 50 anos; (iv) renda familiar não ultrapassa dois salários; e, (iv) a apicultura não é a principal fonte de renda para as famílias. Com a planta elaborada da unidade de extração e beneficiamento de produtos das abelhas para agroindustrialização de mel concebe-se um quadro de prospecção de evolução local das famílias que resultará em renda, além de contribuir com o desenvolvimento regional e econômico. Com a proposta espera-se que esta se reverta em mudanças positivas do perfil socioeconômico dos agricultores familiares.
\end{abstract}

Palavras-chave: agroindústria familiar, apicultura, desenvolvimento rural.

\begin{abstract}
The objective was to develop a proposal for a standard low plant for agro-industrialization of honey in the state of Maranhão with a view to generating income for family farmers. In order to carry out the study, it was carried out in two stages: (i) documentary research for the socioeconomic characterization of family farmers through information gathering at the state's agricultural defense agency; and, (ii) elaboration of a standard individual floor plan respecting the norms of engineering and safe production of food, but, congruent with the socio-economic situation of the evaluated population. With the characterization of the socioeconomic profile, the following information was obtained: (i) male dominance in the activity; (ii) predominance of incomplete elementary education; (iii) majority comprised in the 41 to 50 age group; (iv) family income does not exceed two salaries; and, (iv) beekeeping is not the main source of

\footnotetext{
${ }^{1}$ Programa de Pós-graduação Profissonal em Defesa Sanitária Anima (Curso de Mestrado), Universidade Estadual do Maranhão, raissaaged@gmail.com

${ }^{2}$ Curso de Medicina Veterinária, Universidade Estadual do Maranhão, cellysousa@gmail.com

${ }^{3}$ Coordenadoria de Inspeção de Produtos de Origem Animal, Agência Estadual de Defesa Agropecuária do Estado do Maranhão, cipaaged@ hotmail.com

${ }^{4}$ Doutor em Biodiversidade e Biotecnologia, Universidade Estadual do Maranhão, danilocbezerra15@gmail.com

${ }^{5}$ Doutora em Biotecnologia, Universidade Estadual do Maranhão, nancylenichaves@hotmail.com
} 
income for families. With the elaborated plant of the unit for the extraction and processing of bee products for agro-industrialization of honey, a framework for prospecting the local evolution of families is conceived that will result in income, in addition to contributing to the regional and economic development of the territory. With the proposal, it is expected that this will result in positive changes in the socioeconomic profile of family farmers.

Keywords: family agribusiness, beekeeping, rural development.

\section{Introdução}

A agricultura familiar (AF) apresenta significativa representatividade no Brasil. O Instituto Brasileiro de Geografia e Estatística (IBGE, 2017), por meio do censo agropecuário realizado no ano de 2016, traduz em números essa representatividade: "dos cinco milhões de estabelecimentos agropecuários do Brasil, o equivalente a $77 \%$ pratica a AF. Esses estabelecimentos ocupam $23 \%$ da área total dos estabelecimentos agropecuários e do valor total da produção nacional. Geram, ainda, 67\% do pessoal ocupado no meio rural brasileiro”.

O Maranhão é um estado com forte potencial agropecuário, apresenta diversidade de produção e possui grande parte de sua comunidade rural que sobrevive dos frutos do trabalho da $\mathrm{AF}$ e fornece alimento para milhares de consumidores. Localizado na Região Nordeste, o Maranhão, é composto por 217 municípios, com características semelhantes no que se refere à divisão fundiária e aos aspectos socioeconômicos em que predomina a pequena propriedade rural de base familiar. A economia, pautada na agropecuária, disponibiliza matérias-primas como frutas, hortaliças, grãos (arroz, feijão e milho), mandioca, ovos, carnes, leite e mel.

A produção de mel pela AF assume grande importância no Maranhão. De acordo com o último censo agroepecuário do IBGE, o Estado produziu no ano de 2016, 1.700 toneladas de mel, ficando atrás somente dos estados da Bahia (3.590 toneladas) e Piauí (3.000 toneladas). No ranking nacional, o Maranhão ocupa a oitava colocação, sendo o estado do Rio Grande do Sul o maior produtor do país (IBGE, 2017).

Contudo, a agroindustrialização do mel por meio das agroindústrias familiares, que apresenta como finalidade agregar valor e renda aos pequenos produtores rurais, ainda, é incipiente no Brasil. Pelos aspectos supracitados que evidenciam a importância da AF para o País e o Maranhão, houve a necessidade dos governos discutirem e implantarem políticas públicas que promovessem a formalização das agroindústrias familiares para que estas aumentem seu mercado de comercialização.

No estado do Maranhão, a agroindústria familiar, foi transformada em Política Pública por meio da Lei Estadual n ${ }^{\circ} 10.086$, de 20 de maio de 2014, que dispõe sobre a habilitação sanitária de estabelecimento agroindustrial familiar, de pequeno porte ou artesanal, para 
elaboração e comercialização de produtos da agroindústria no estado da Maranhão e dá outras providências. A referida lei em seu Artigo $1^{\circ}$ institui: "todo estabelecimento agroindustrial familiar, de pequeno porte ou artesanal, que elabore e comercialize produtos no âmbito do Estado do Maranhão, será habilitado pelo órgão de controle ou de defesa sanitária competente, nos termos desta Lei e de seu regulamento" (MARANHÃO, 2014).

Ainda no âmbito das políticas públicas, no ano de 2014, foi criado na Coordenadoria de Inspeção de Produtos de Origem Animal (CIPA) da Agência Estadual de Defesa Agropecuária do estado do Maranhão (AGED-MA), o setor de Agroindústria Familiar, Pequeno Porte e Artesanal do Serviço de Inspeção Estadual (S.I.E) com a premissa de registrar e fiscalizar as agroindústrias familiares, de pequeno porte e artesanal, gerando emprego e renda ao pequeno produtor rural. O referido setor da AGED-MA constatou no ano de sua criação a inexistência de agroindústrias registradas no SIE.

Face ao panorama apresentado, questões centrais devem integrar as discussões da AF como, a natureza e a sustentabilidade das organizações constituídas, o que perpassa, invarialvelmente, pelo aspecto da qualidade dessas agroindústrias e não, meramente, a quantidade. Ao se reportar às agroindústrias familiares, a implantação destas dependerá de sua formalização. Para isso, são necessários diferentes tipos de registros, como os relativos à questão fiscal e tributária do grupo de agricultores familiares, além dos de ordem sanitária e ambiental. Especificamente sobre a regularização sanitária, esta se refere ao licenciamento sanitário da agroindústria familiar e seus produtos - processo que permitirá a fabricação dos produtos em conformidade com normas sanitárias vigentes e a posterior inserção dos produtos elaborados no mercado, com segurança e qualidade.

Ainda referente à regularização sanitária, existe a necessidade da apresentação de plantas e memoriais que descrevem como será a construção do empreendimento e quais os materiais utilizados, o que representa um gargalo para muitos agricultores familiares pelo custo financeiro e burocrático associado. Nesse contexto, objetivou-se elaborar uma proposta de planta baixa padrão para agroindustrialização do mel no estado do Maranhão com vistas à geração de renda para agricultores familiares.

\section{Material e Métodos}

\section{Tipo do estudo}

Este trabalho é classificado quanto à natureza do método em pesquisa qualitativa e quanto à utilização dos resultados em pesquisa aplicada. Segundo Gerhardt e Silveira (2009), “a pesquisa qualitativa é voltada para a compreensão de um grupo social sem a preocupação 
com representação numérica" e "a pesquisa aplicada leva o conhecimentos para aplicação prática, envolvendo verdades e interesses locais". Quanto aos fins da pesquisa, é do tipo pesquisa descritiva, ou seja, têm como objetivo primordial a descrição das características de determinada população ou fenômeno ou o estabelecimento de relações entre variáveis (GIL, 2008).

\section{População do estudo e levantamento do perfil socioeconômico}

A população de estudo foi composta por apicultores com agroindústrias familiares em processo de registro na CIPA, Setor de Agroindústria Familiar, Pequeno Porte e Artesanal da AGED-MA. O instrumento de coleta das informações foi a pesquisa bibliográfica documental, por meio de levantamento de informações em cadastros do agricultor familiar no setor de inspeção estadual do estado do Maranhão em que foi possível o levantamento das seguintes informações: (i) município de origem; (ii) gênero; (iii) faixa etária; (iv) escolaridade; (v) renda; (vi) tempo na atividade; (vii) apicultura como atividade principal; (vii) participação em ententidade associativa; e, (ix) área da propriedade.

\section{Planta baixa individual padrão}

É importante ressaltar que este trabalho teve parceria com a AGED-MA e a Agência Estadual de Extensão Rural e Pesquisa Agropecuária do Maranhão (AGERP-MA) que trabalham junto aos apicultores, população alvo deste estudo. O Programa de Pós-graduação Profissional em Defesa Sanitária Animal da Universidade Estadual do Maranhão (UEMA), também, foi parceiro na execução da pesquisa.

A planta baixa individual padrão para uma Unidade de Extração e Beneficiamento de Produtos das Abelhas foi elaborado por meio de uma equipe multidisciplinar (fiscais estaduais agropecuários/médicos veterinários, técnicos, engenheiros, arquitetos e graduanda em medicina veterinária) em consonância com a Norma Brasileira (NBR) 13532 de 1995 que trata da elaboração de projetos e edificação (ABNT, 1995); Lei Estadual 10.086/2014 que dispõe sobre a habilitação sanitária de estabelecimento agroindustrial familiar, de pequeno porte ou artesanal (MARANHÃO, 2014); Instrução Normativa $\mathrm{n}^{\circ} 11$, de 20 de outubro de 2000, que aprova o Regulamento Técnico de Identidade e Qualidade do Mel (BRASIL, 2000); e, o Decreto 9.013 de 2017 que aprova o Regulamento de Inspeção Industrial e Sanitária de Origem Animal - RIISPOA (BRASIL, 2017).

A equipe também produziu o memorial econômico-sanitário para a unidade de extração e beneficiamento de produtos das abelhas, além do memorial descritivo que discrimina os materiais a serem utilizados no projeto e uma planilha de equipamentos e 
utensílios necessários para as atividades atinentes ao beneficiamento do mel na agroindústria.

\section{Resultados e Discussão}

Foram lavantadas nove agroindústrias de mel em processo de registro na AGED-MA. Destas, seis $(66,67 \% ; n=6 / 9)$ com processo de formalização vigente ${ }^{4}$; contudo, apenas um proprietário $(11,11 \% ; n=1 / 9)$ entregou o projeto de construção das agroindústrias.

Rosário, Carolina e Maranhãozinho, são os municípios de origem dos agricultores familiares e os locais para futura implantação das agroindústrias familiares de mel. Segundo a regionalização do governo do estado do Maranhão em regiões de planejamento (MARANHÃO, 2008), os referidos municípios estão localizados, respectivamente, nas regiões do Baixo Munim, Chapada da Mesas e Gurupi que apresentam em comum potencialidades para realização da apicultura e meliponicultora.

Marques et al. (2011) destacam que o desenvolvimento da atividade apícola no estado do Maranhão fundamenta-se na existência de vegetação, condições edáficas e climáticas, diversidade de espécies disponíveis nas diferentes situações de habitats que podem proporcionar grande disponibilidade de néctar e pólen. Portanto, a apicultura representa uma possibilidade real de negócio e inclusão social, mesmo para quem dispõe de poucos recursos.

Adicionalmente, a apicultura é uma atividade que não exige dedicação exclusiva, propiciando aos apicultores desenvolverem atividades concomitantes sem prejuízo à criação de abelhas. Isso possibilita ocupação aos membros da família e viabiliza a geração de renda, assegurando a diversificação da produção na pequena propriedade. Segundo Schneider (2010), a combinação de múltiplas ocupações dos agricultores familiares, desenvolvidas no próprio estabelecimento ou fora dele, caracteriza a pluriatividade da agricultura familiar.

Referente às variáveis socioeconômicas, a pesquisa bibliográfica documental permitiu conhecer o perfil dos apicultores com agroindústrias familiares em processo de formalização vigente no estado do Maranhão (Tabela 1).

\footnotetext{
${ }^{4}$ Formalização vigente: caracterizada por movimentação do mesmo com a inclusão de documentos requeridos pelo S.I.E
} 
Tabela 1. Característica socioeconômicas de agricultores familiares com agroindústrias de mel em processo de formalização vigente no órgão de defesa agropecuária do estado do Maranhão, 2020.

\begin{tabular}{|c|c|c|c|}
\hline \multicolumn{2}{|c|}{ Variáveis } & \multirow{2}{*}{$\begin{array}{c}\text { Quantidade } \\
06\end{array}$} & \multirow{3}{*}{$\begin{array}{c}\begin{array}{c}\text { Percentual } \\
(\%)\end{array} \\
100 \\
00\end{array}$} \\
\hline & Masculino & & \\
\hline Gênero & Feminino & 00 & \\
\hline \multirow{3}{*}{ Faixa etária } & $31-40$ & 01 & 16,67 \\
\hline & $41-50$ & 05 & 83,33 \\
\hline & $>50$ & 00 & 00 \\
\hline \multirow{3}{*}{ Escolaridade } & Fundamental incompleto & 06 & 100 \\
\hline & Médio Completo & 00 & 00 \\
\hline & Superior completo & 00 & 00 \\
\hline \multirow{2}{*}{$\begin{array}{ll}\text { Renda } & \text { (salários } \\
\text { mínimos) } & \end{array}$} & Até 2 & 06 & 100 \\
\hline & $>5$ & 00 & 00 \\
\hline \multirow{2}{*}{$\begin{array}{l}\text { Tempo na atividade } \\
\text { de apicultura (anos) }\end{array}$} & 02 a 05 anos & 00 & 00 \\
\hline & $\geq 05$ & 06 & 100 \\
\hline \multirow{2}{*}{$\begin{array}{l}\text { Apicultura como } \\
\text { atividade principal }\end{array}$} & Sim & 00 & 00 \\
\hline & Não & 06 & 100 \\
\hline \multirow{2}{*}{$\begin{array}{l}\text { Participa de alguma } \\
\text { entidade associativa }\end{array}$} & Sim & 06 & 100 \\
\hline & Não & 00 & 00 \\
\hline \multirow{2}{*}{$\begin{array}{l}\text { Área da propriedade } \\
\text { (hectares) }\end{array}$} & 0,5 a 01 & 05 & 83,33 \\
\hline & até 05 & 01 & 16,67 \\
\hline
\end{tabular}

Fonte: Própria (2020).

A partir da obtenção do perfil dos apicultores, pode-se constatar que $100 \%$ destes são profissionais com baixo nível de escolaridade e do gênero masculino e a maioria $(83,33 \%)$ está compreendidos na faixa etária de 41 a 50 anos. Todos trabalham na atividade há pelo menos cinco anos, o que evidencia conhecimento e experiência em relação à apicultura.

A renda dos agricultores familiares é de dois salários mínimos e 100\% destes não tem a apicultura como atividade principal. De posse dessas informações, pode-se enquadrar os referidos agricultores familiares na diversificação da produção como forma de reprodução familiar. Para Silva e Mendes (2015), a diversificação das atividades produtivas é uma importante estratégia de reprodução da $\mathrm{AF}$, pois, não apenas diversifica a variedade de produtos comercializáveis, como também assegura a subsistência da família. E esta pode ser compreendida como forma de resistência ao modelo capitalista que se incorporou no meio rural.

Acerca da discussão sobre a rentabilidade da apicultura para os agricultores familiares avaliados, é importante destacar o papel da Assistência Técnica e Extensão Rural (ATER) no sucesso de qualquer atividade. A ATER é fundamental em qualquer atividade comercial e ao se reportar à assistência técnica rural pode-se inferir que esta é uma atividade essencial para o 
desenvolvimento da AF, sobretudo, no que se refere a inserção e viabilização de novas práticas produtivas.

Quanto ao nível de organização dos agricultores familiares constatou-se que estes estão organizados em associação ou cooperativa o que permite aos mesmos algumas vantagens, como assistência técnica e acesso a linhas de crédito. Para Mumic, Aguiar e Livramento (2015), os pequenos produtores rurais encontram dificuldades na comercialização de seus produtos no meio urbano e encontram nos incentivos e meios que a associação lhes oferecem, oportunidades para se desenvolverem e competirem no mercado.

Os apicultores com agroindústria familiar em processo de registro são produtores com até cinco hectares de área, classificados como empreendimentos da agricultura familiar de acordo com Lei $\mathrm{n}^{\mathrm{o}} 10.086$ de 2014:

"empreendimento de propriedade sob a gestão individual ou coletiva de
agricultores familiares, nos termos do art. $3^{\circ}$ da Lei Federal $\mathrm{n}^{\circ} 11.326$, de 24
de julho de 2006 , com área útil construída não superior a $250 \mathrm{~m}^{2}$ (duzentos e
cinquenta metros quadrados), que, por motivação de natureza econômico e
social, visam agregar valor aos produtos que não conseguem comercializar
"in natura", e dispõem de instalações mínimas conforme critérios definidos
em regulamento (MARANHÃ 2014 ).

Voltando à questão da agroindustrialização, foram contabilizados três apicultores com processo de registro das agroindústrias vencidos e cinco com processos vigentes, porém apenas um apresentou o projeto de construção das agroindústrias. Com a pesquisa bibliográfica documental, não foi possível determinar as causas da não movimentação do processo a mais de dois anos, bem como a não apresentação do projeto de construção. Mas, pode-se pontuar como possíveis gargalos a questão financeira ou burocrática. Nesse interim, para o registro sanitário de agroindústrias familiares são exigidos documentos, entre eles o projeto técnico da construção constituído por planta baixa e memoriais descritivo e econômico-sanitário da construção (plantas de layout de equipamentos, localização, cortes e fachadas e hidráulica), o que representa custo por demandar de profissional habilitado para a execução do mesmo.

No sentido de reduzir as situações de não movimentação de processos de formalização e ao mesmos tempo, fomentar a agroindustrialização de mel oriundo da AF no Maranhão, elaborou-se uma proposta de planta baixa individual padrão já aprovada no órgão de defesa e inspeção do Maranhão que será disponibilizada aos agricultores familiares que manifestarem interesse e, assim, facilitar a tramitação dos processos de registro. 
A planta padrão elaborada refere-se à construção de uma Unidade de Extração e Beneficiamento de Produtos das Abelhas ${ }^{5}$ em consonância com o Decreto n ${ }^{\circ}$ 9.013, de 29 de março de 2017, respeitando as normas da construção civil (engenharia) e da produção segura de alimentos, mas, congruentes à situação sócio-econômica dos agricultores familiares (Figura 1).

Figura 1. Modelo de fachada com nome de fantasia de uma unidade de extração e beneficiamento de produtos das abelhas para agroindustrialização de mel oriundo da agricultura familiar no estado do Maranhão.

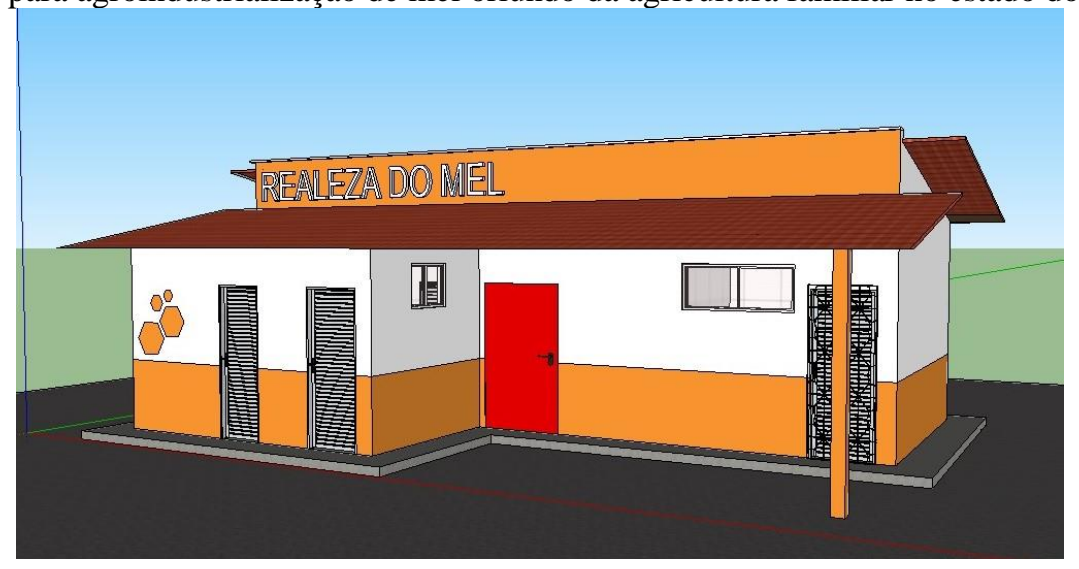

Fonte: Própria (2020).

Na planta padrão da Unidade de Extração e Beneficiamento de Produtos das Abelhas constam instalações adequadas, respeitando o layout de produção que indica por onde entrará a matéria-prima e o caminho que a mesma percorrerá no interior das instalações até ser expedida como mel centrifugado, decantado e envasado em garrafas plásticas de 280 gramas (produto final) (Figura 2). A capacidade de beneficiamento mensal da agroindústria será de 2,8 toneladas. Este será proveniente de unidade familiar de apicultores em que trabalharão até cinco agricultores familiares.

${ }^{5}$ Unidade de Extração e Beneficiamento de Produtos das Abelhas: estabelecimento destinado ao recebimento de matérias-primas de produtores rurais, à extração, ao acondicionamento, à rotulagem, à armazenagem e à expedição dos produtos de abelhas, facultando-se o beneficiamento e o fracionamento (BRASIL, 2017). 
Figura 2. Planta padrão de unidade de extração e beneficiamento de produtos das abelhas para agroindustrialização de mel oriundo da agricultura familiar no estado do Maranhão.

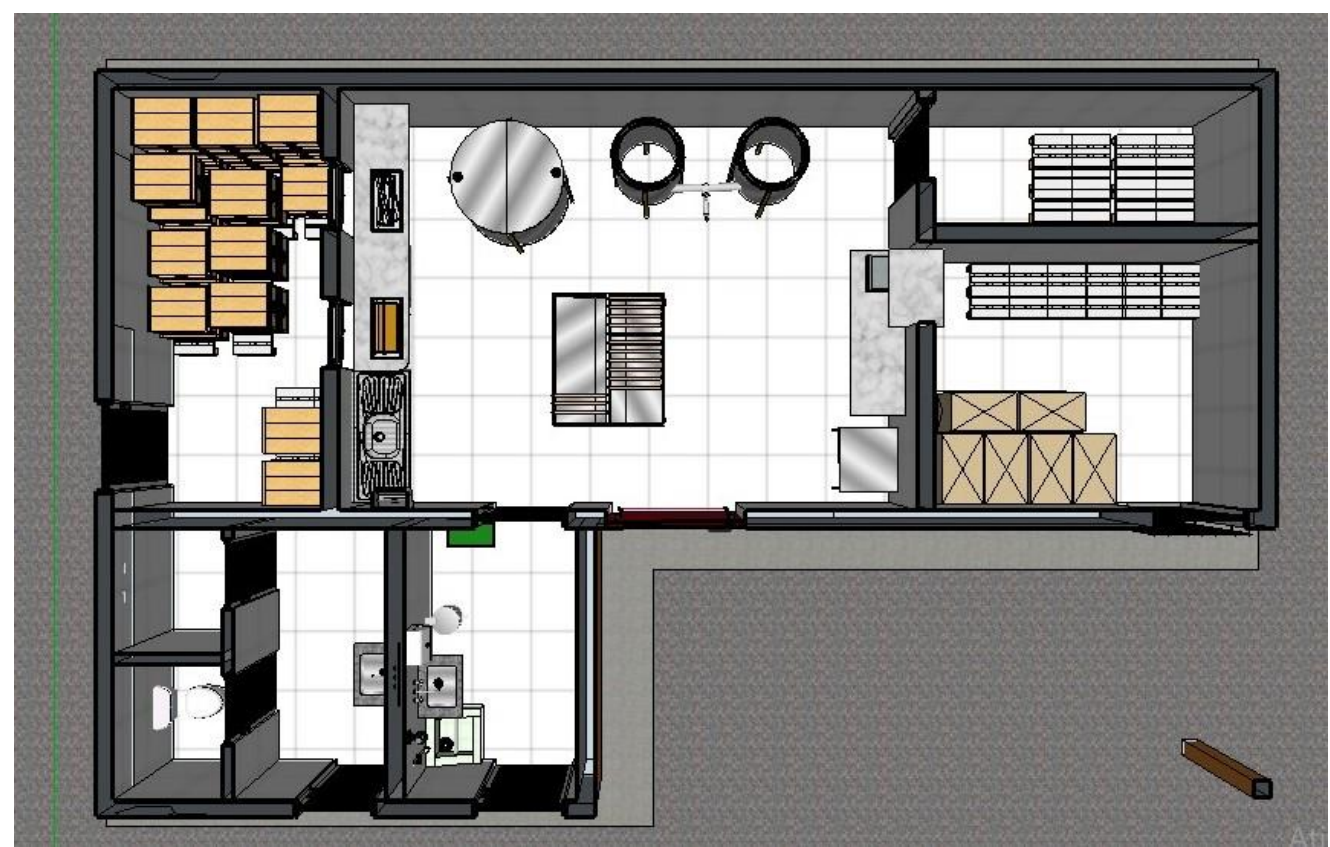

Fonte: Própria (2020).

O local para recepção da matéria-prima, com $6,64 \mathrm{~m}^{2}$ de área, tem capacidade para recebimento e armazenamento de 27 melgueiras. A recepção situa-se no interior da agroindústria e será coberta, o que minimizará o acesso de vetores, animais sinantrópicos e poeira. Dessa área, os quadros serão retirados das melgueiras e passarão para a sala de extração por meio de um óculo. Nessa sala, com área útil de $18,50 \mathrm{~m}^{2}$, os quadros serão desoperculados em mesa desoperculadora e na sequência o mel será colocado na centrífuga. Após essa etapa, será filtrado com o auxílio de uma peneira que estará sobre um balde de material inoxidável ou de material plástico resistente e atóxico com capacidade de $25 \mathrm{Kg}$.

O mel armazenado no balde será conduzido para decantadores e permanecerá neste, por no mínimo 48 horas, em seguida será colocado na maquina envasadora por meio de balde para posterior envase em embalagem primária (garrafas plásticas de 280 gramas). Logo após, o mel embalado e rotulado, será colocado em embalagens secundárias (caixas de papelão) e passará por meio de um ocúlo para uma área com $6,49 \mathrm{~m}^{2}$, denominada área de armazenamento e expedição em que será mantido sobre estrados de polipropileno até a expedição. O mel embalado será transportado em caminhonete para ser comercializado no mercado local e regiões circunvizinhas dentro do estado.

Na planta padrão consta ainda um depósito de embalagens com área de 3,41 $\mathrm{m}^{2}$ para o acondicionamento de embalagens e um vestiário e banheiro com área de $5,02 \mathrm{~m}^{2}$. Atenção singular foi dispensada à segurança com a existência de bloqueio sanitário, composto de lava 
botas, tapete sanitário, lavatório de mãos, dispensador de sabão líquido, papel toalha e lixeira com tampa com acionamento pedal, e uma saída de emergência e disposição de extintores de incêndio.

Será disponibilizado aos agricultores familiares o memorial econômico-sanitário e alguns dos aspectos constantes nesse documento são sumarizados abaixo:

- Fonte de abastecimento de água: a unidade de extração e beneficiamento de produtos das abelhas será abastecido por água potável. Da fonte de abastecimento, a água será captada e distribuída por rede; será clorada por meio da instalação de bomba dosadora na entrada da caixa. Então, será armazenada em caixa d'água com capacidade para 1.000 litros que compreenderá o reservatório da agroindústria.

- Fiscalizações sanitárias: As fiscalizações na agroindústria serão periódicas e não haverá sala destinada ao serviço de inspeção oficial. Planilhas de controle e formulários serão mantidos na Unidade Local de Sanidade Animal e Vegetal a qual o estabelecimento estará vinculado.

- Destino das águas servidas: A instalação hidráulica será completa e pronta para ser instalada na sua rede de esgoto e ser alimentada por um ponto hidráulico. O setor administrativo terá esgotamento sanitário separado do esgoto industrial, sendo que o sistema de esgoto será composto de fossa séptica para água proveniente da área administrativa e uma estação de tratamento de esgoto (ETE) para área de produção conforme projeto sanitário.

Será disponibilizado aos agricultores familiares o memorial descritivo que sumariza os materiais a serem utilizados no projeto (Tabela 2). Estes foram escolhidos, essencialmente, com vistas a não transmissão de substâncias indesejáveis à matéria-prima e ao produto acabado e, nas áreas de manipulação, ponderou-se para as condições higiênico-sanitárias das paredes, pisos, teto, portas e janelas que, de maneira geral, serão impermeáveis e laváveis, e planejadas no sentido de minimizar o acúmulo de sujeira e condensação de água.

$\mathrm{O}$ custo total da obra é de $\mathrm{R} \$$ 82.274,16 valor considerado baixo para um estabelecimento elaborador de alimentos, mas, adequado às exigências sanitárias e pautado, sobretudo, na questão sócio-econômica da população amostrada. 
Tabela 2. Memorial descritivo de unidade de extração e beneficiamento de produtos das abelhas para agroindustrialização de mel oriundo da agricultura familiar no estado do Maranhão.

\begin{tabular}{ll}
\hline \multicolumn{1}{c}{ Dados da Obra } & \multicolumn{1}{c}{ Especificações } \\
\hline Clientes & Agricultores familiares de mel \\
Natureza do estabelecimento & Unidade de extração e beneficiamento de produtos das \\
abelhas \\
Área a ser construída & $50,97 \mathrm{~m}^{2}$ \\
Área útil & $44,32 \mathrm{~m}^{2}$ \\
Recuo do alinhamento da rua & $5,0 \mathrm{~m}$ \\
Duração provável da obra & 90 dias \\
Pé direito das áreas limpa e suja & $3,50 \mathrm{~m}$ \\
Área coberta & $103,00 \mathrm{~m}^{2}$ \\
Madeiramento e cobertura & Cobertura em telha tipo chapa ondulada com estrutura de \\
& madeira \\
Forro & Policloreto de vinila \\
Portas & Alumínio \\
Óculos & Alumínio \\
& Revestimento interno cerâmica branca \\
Revestimento geral & Paredes até $2,00 \mathrm{~m}$ de cerâmica branca e o restante de \\
& reboco liso com argamassa de cimento e areia na \\
Pavimentação externa & proporção de $1: 5$ \\
Esquadrias & Blocos de concreto intertravado de 10 cm de espessura \\
Impermeabiliação & Janelas de alumínio e vidro de correr \\
Instalação d'água & Feita com polímetros \\
Sistema de esgoto & Tubos de policloreto de vinilo (PVC), com caixa d'água \\
Pintura geral & elevada de 1.000 litros \\
Custo provável da obra & Ligado a fossas sépticas , sumidouros \\
\hline
\end{tabular}
Fonte: Própria (2020).

De igual forma será disponibilizada aos agricultores familiares planilha de equipamentos, conforme sumarizado na Tabela 3. O custo com os equipamentos será de $\mathrm{R} \$$ 20.297,85, o que resultará em valor total da unidade de extração e beneficiamento de produtos das abelhas no valor de $\mathrm{R} \$ 102.572,01$ (obra + equipamentos). Em referência aos equipamentos a serem utilizados na agroindustrialização do mel, estes serão de material resistente, não absorvente e não corrosivo, no sentido de evitar que odores, sabores e substâncias tóxicas sejam transmitidas à matéria-prima e ao produto acabado, seja por contato direto ou indireto. 
Tabela 3. Relação de equipamentos e utensílios para a unidade de extração e beneficiamento de produtos das abelhas para agroindustrialização de mel oriundo da agricultura familiar no estado do Maranhão.

\begin{tabular}{lcc}
\multicolumn{1}{c}{$\begin{array}{c}\text { Equipamentos e } \\
\text { Utensílios }\end{array}$} & Quantidade & Valor (R\$) \\
\hline Centrífuga para 64 & 01 & $6.000,00$ \\
quadros & 02 & 240,00 \\
Peneira inox & 02 & 46,00 \\
Baldes plásticos atóxicos & 04 & 200,00 \\
Bandejas Polietileno & 01 & $3.200,00$ \\
Mesa desoperculadora & 02 & $2.900,00$ \\
para 64 quadros & 01 & $5.000,00$ \\
Decantador de 400kg & 01 & 579,00 \\
Envasadora & 01 & 350,00 \\
Armário para embalagem & 01 & 97,85 \\
Armário para utensílios & 05 & 125,00 \\
Armário para produtos de & 26 & $1.560,00$ \\
limpeza & & $\mathbf{2 0 . 2 9 7 , 8 5}$ \\
Garfo desoperculador & & \\
Paletes plásticos & \multicolumn{1}{c}{ Total } &
\end{tabular}

Fonte: Própria (2020).

Nesse ponto da discussão é oportuno enfatizar que a agroindústria familiar é uma estratégia de reprodução social importante para as famílias rurais de um local, área ou território, sobretudo, referente aos aspectos econômico, social e produtivo. Do ponto de vista econômico e produtivo esta atividade é sinônimo de geração de renda, empregos e divisas para o local e os agricultores familiares que a praticam e ajudar a evitar o exôdo rural. Portanto, a agroindústria cumpre um importantíssimo papel social, ou seja, mantém o homem no meio rural trabalhando, produzindo e vivendo com a sua família.

\section{Conclusões}

Os apicultores com agroindústria de mel em processo de registro no estado do Maranhão apresentam o seguinte perfil socioeconômico: gênero masculino, nível educacional baixo, longa experiência com a atividade produtiva, apesar desta não configurar como atividade principal na propriedades rural, estando de alguma forma organizados em associações ou cooperativas. Com a planta individual padrão da unidade de extração e beneficiamento de produtos das abelhas para agroindustrialização de mel concebe-se um quadro de prospecção da evolução de desenvolvimento local das famílias com a agroindustrialição do mel que resultará em renda, além de contribuir com o desenvolvimento regional e econômico do território, bases fundamentais da agricultura familiar. Com a 
proposta espera-se que esta se reverta em mudanças positivas do perfil socioeconômico dos agricultores familiares.

\section{Referências}

ASSOCIAÇÃO BRASILEIRA DE NORMAS TÉCNICAS. NBR 13532. Elaboração de projetos de edificações - Arquitetura. 1995. Disponível em: https://www2.unifap.br/arquitetura/files/2013/01/NBR-13532-Projeto-de-Arquitetura-.pdf. Acesso em: 02 jun 2020.

BRASIL. Ministério da Agricultura, Pecuaria e Abastecimento. Instrução Normativa $n^{\circ} 11$, de 20 de outubro de 2000. Aprova o Regulamento Técnico de Identidade e Qualidade do Mel. Diário Oficial [da] República Federativa do Brasil, Brasília, DF, 23 de outubro de 2000. Disponível em: http://www.dourados.ms.gov.br/wp-content/uploads/2016/05/RTIQ-Melcompleto-IN-11_2000.pdf. Acesso em: 02 jun 2020.

BRASIL. Presidência da República. Decreto n ${ }^{\circ} 9.013$ de 29 de março de 2017. Regulamenta a Lei $\mathrm{n}^{\circ} 1.283$, de 18 de dezembro de 1950 , e a Lei $\mathrm{n}^{\circ} 7.889$ de 23 de novembro de 1989 que dispõe sobre a inspeção industrial e sanitária de produtos de origem animal. Diário Oficial [da] República Federativa do Brasil, Brasília, DF, 29 de março de 2017. Disponível em: http://www.planalto.gov.br/ccivil_03/_ato2015-2018/2017/decreto/D9013.htm. Acesso em: 02 jun 2020.

GERHARDT, T. E.; SILVEIRA, D. T. (org). Métodos de Pesquisa. Porto Alegre: Editora da UFRGS, 2009.

GIL, A. C. Métodos e técnicas de pesquisa social. São Paulo: Atlas, 2008. 220p.

INSTITUTO BRASILEIRO DE GEOGRAFIA E ESTATÍSTICA. 2017. Censo Agroepecuário. Disponível em: https://censos.ibge.gov.br/agro/2017/resultados-censo-agro2017.html. Acesso em: 02 jun 2020.

MARANHÃO. Governo do Estado do Maranhão. Secretaria de Estado do Planejamento e Orçamento. Regiões de Planejamento do Estado do Maranhão. Instituto Maranhense deEstudos Socioeconômicos e Cartográficos, Universidade Estadual do Maranhão .São Luís: SEPLAN, 2008. 103 p.

MARANHÃO. Governo do Estado do Maranhão. Lei no 10.086, de 20 de maio de 2014. Dispõe sobre a habilitação sanitária de estabelecimento agroindustrial familiar, de pequeno porte ou artesanal, para elaboração e comercialização de produtos da agroindústria no Estado da Maranhão e dá outras providências. Diário Oficial [do] Estado do Maranhão, São Luís, MA, 20 de maio de 2017. Disponível em: http://www.aged.ma.gov.br/files/2017/06/LEI10.086-AGROINDUSTRIA-FAMILIAR.pdf Acesso em: 02 jun 2020.

MARQUES Jr., L. et al. Levantamento da flora apícola em Santa Luzia do Paruá. Sudoeste da Amazônia, Maranhão. Acta Botanica Brasilica, v. 25, n. 1, p.141-149. 2011.

MUMIC, B.; AGUIAR, K. A. P.; LIVRAMENTO, D. E. do. A importância do associativismo na organização de produtores rurais. Revista de Iniciação Científica da LIBERTAS, v. 5, n. 1, p. 5-22, 2015. 
SCHNEIDER, S. A. A pluriatividade na agricultura familiar, 2.ed. Porto Alegre: Editora da UFRGS, 2010.

SILVA, J. M.; MENDES, E. P. P. Agricultores familiares e reprodução social: as comunidades Cruzeiros dos Martírios e Paulistas no município de Catalão (GO). In: NEVES, A.F. et al. (orgs.). Coletânea Interdisciplinar em Pesquisa, Pós-Graduação e Inovação. v 1. [livro eletrônico]. São Paulo: Blucher, 2015. 